Traditional Medicine and Modern Medicine

Vol. 2, No. 2 (2019) 67-74

(C) Institutes of Integrative Medicine, Fudan University and

World Century Publishing Corporation

DOI: $10.1142 / \mathrm{S} 2575900019500083$

\title{
Protective effect and mechanisms of ginsenoside Rg1 against MDA-suppressed proliferation in mesenchymal stem cells derived from murine bone marrow
}

\author{
Ye $\mathrm{Li}^{1, \$}$, Cheng $\mathrm{Ma}^{2, *}$, Zhe $\mathrm{Lv}^{3}$, Chang-Feng Shao ${ }^{1}$, Jun Zhang ${ }^{4}$, Wenye Geng ${ }^{2,5, *}$ and Lan Zheng ${ }^{1, \dagger}$ \\ ${ }^{1}$ Hunan Provincial Key Laboratory of Physical Fitness \\ and Sports Rehabilitation, Hunan Normal University \\ Changsha 410012, P. R. China \\ ${ }^{2}$ Department of Integrative Medicine, Huashan Hospital, Fudan University \\ Shanghai 200040, P. R. China \\ ${ }^{3}$ Liaocheng 4th Hospital, Shandong Province, P. R. China \\ ${ }^{4}$ Hunan Vocational College of Science \& Technology \\ Changsha 410004, Hunan, P. R. China \\ ${ }^{5}$ Department of Thoracic Surgery \\ Qingpu Traditional Chinese Medicine Hospital \\ Shanghai 60518120, P. R. China \\ *drug@fudan.edu.cn \\ †lanzheng@hunnu.edu.cn
}

Received 26 April 2019; Accepted 30 May 2019; Published 18 July 2019

\begin{abstract}
Objective: The present study was designed to investigate the cytoprotective effects of ginsenoside $\operatorname{Rg} 1$ (GS-Rg1) against malondialdehyde (MDA)-suppressed proliferation of the mesenchymal stem cells (MSCs) and its possible mechanisms in vitro.

Methods: Murine bone marrow-derived MSCs were treated with GS-Rg1 (10, 50, $100 \mathrm{mg} / \mathrm{L})$ for $24 \mathrm{~h}$ before being incubated with MDA in vitro, CFU-Fassay, the cell viability and BrdU incorporation assay were examined, the expression of cyclin-dependent kinase 2 (CDK2), p21 and cyclin E of MSC were examined by Q-RT-PCR and Western blotting.

Results: The results showed that the number and size of murine bone marrow MSC colonies, the number of colonyforming cells, methyl thiazolyltetrazolium (MTT) absorbed value greatly and percentage of BrdU-positive cells increased significantly in MSC pretreated with GS-Rg1. GS-Rgl pretreatment markedly decreased the expression level of p21 and increased the expression of CDK2 and cyclin E. GS-Rg1 protects MSCs from MDA-suppressed proliferation. Conclusion: The protective mechanism could be related to its ability to increase the expression of CDK2 and cyclin E, and to reduce the expression of $\mathrm{p} 21$.
\end{abstract}

Keywords: Ginsenoside Rg1; mesenchymal stem cells; malondialdehyde; proliferation; cell cycle.

\section{Introduction}

Mesenchymal stem cells (MSCs) are characterized by high proliferation and multi-directional differentiation, and are easy to obtain and cultivate. ${ }^{1-3}$ The decreased proliferation capacity of MSCs is an important manifestation in the aging process of MSCs, ${ }^{4-6}$ as well as an important part of the

${ }^{*}, \dagger$ Corresponding authors.

\#Ye Li and Cheng Ma contributed equally to this work. 
mechanism of various senile degenerative diseases. Reactive carbonyl species (RCS) is a common active intermediate product of lipid peroxidation and non-enzymatic glycosylation, and has strong biological reaction activity. When it attacks the amino and mercapto groups of biomacromolecules such as proteins and nucleic acids, the structural changes and functional loss of biomacromolecules occur, and thus resulting in a series of pathophysiological changes. Therefore, it plays a vital role in aging and the pathological processes of various diseases. $^{7}$ Malondialdehyde (MDA) is a representative RCS, which induces senescence-related changes in bone marrow MSCs and is closely related to senile osteoporosis. ${ }^{8}$ Our previous studies showed that MDA had an inhibitory effect on MSC proliferation, and maintained the cell cycle at the $G 2 / M$ phase.

Cell cycle regulatory proteins are of vital importance in cell proliferation, differentiation, senescence and death. Studies showed that p21 can interact with cyclin E and cyclin-dependent kinase 2 (CDK2) compounds. It blocks cells in the $G 1$ phase and is an important part in regulating cell proliferation.

Ginsenoside $\operatorname{Rg} 1$ (GS-Rg1) is one of the main active ingredients of ginsenosides. Studies showed that GS-Rg1 is functioning in anti-oxidation, anti-stress, anti-aging and protecting cells from the damage of toxic substances. ${ }^{9-12}$ However, whether it has the protective effect on the reduction of proliferative ability caused by carbonyl stress is still unclear. In this study, MDA-induced carbonyl stress in MSCs was used to observe whether ginsenoside $\operatorname{Rg} 1$ has the function of antiaging, and the changes in protein expression levels of $\mathrm{p} 21$, CDK2 and cyclin E will also be observed to explore the cell cycle regulation mechanism of $\operatorname{Rg} 1$ in anti-aging.

\section{Material and Methods}

\section{Laboratory animals and reagents}

1, 1, 3, 3-tetramethoxy propane (TMP, Fluka Co. Ltd.), L-DMEM culture medium (GIBICO Co. Ltd.), Hyclone, BALB/c mice (Hunan Slake kingda laboratory animals, Co. Ltd.), dimethyl sulfoxide (DMSO) and methyl thiazolyltetrazolium (MTT) (Sigma Co. Ltd.); 5'-bromodeoxyuridine (5-BrdU) (Sigma Co. Ltd.), anti-5-BrdU and anti-CDK2 Monoclonal Antibody (Santa Cruz biotechnology Co. Ltd.), anti-p21 and anti-cyclin E Monoclonal Antibody (BD PharMingen Co. Ltd.) are used.

\section{Solution preparation}

Ginsenoside storage solution: A certain amount of GS-Rg1 powder was weighed. According to the weights, GS-Rg1 was dissolved with a certain volume of anhydrous ethanol, and then the dissolved GS-Rg1 ethanol solution was added to
DMEM culture solution drop-by-drop to a final ethanol concentration of $1.25 \%$ (volume fraction), and was filtered and sterilized, and stored at $4{ }^{\circ} \mathrm{C}$ for later use. Ginsenoside storage solution with a concentration of $400 \mathrm{mg} / \mathrm{L}$ was prepared with DMEM solution of the corresponding volume.

MDA solution: $50 \mathrm{~mol} / \mathrm{L}$ of MDA storage solution was prepared by acid hydrolysis of 1, 1, 3, 3-tetramethoxy propane (TMP). $0.423 \mathrm{~mL}(2.5 \mathrm{mmol} / \mathrm{L})$ of TMP and $2.0 \mathrm{~mL}$ $(1.0 \mathrm{~mol} / \mathrm{L})$ of HCL were mixed, and the mixed solution was oscillated in $40^{\circ} \mathrm{C}$ water bath to hydrolyze for $2.5 \mathrm{~min}$. After TMP was completely hydrolyzed, $\mathrm{pH}$ value was adjusted to 7.2 with $6.0 \mathrm{~mol} / \mathrm{L} \mathrm{NaOH}$, and finally the volume was fixed to $50 \mathrm{~mL}$ with PBS. The UV absorption of the solution at $267 \mathrm{~nm}(\varepsilon=31,500)$ was measured to determine whether it meets the required concentration.

\section{MSC cultured in vitro}

Bilateral femurs of mice were taken out under aseptic condition, the medullary cavities were rinsed, and bone marrow was collected to prepare bone marrow single-cell suspension. Bone marrow cells were seeded in DMEM containing 10\% fetal bovine serum with the inoculum density of $5 \times 106 / \mathrm{mm}^{2}$ bone marrow nucleated cells at the bottom of culture bottle. Cells were cultured under the condition of saturated humidity, with the temperature of $37^{\circ} \mathrm{C}$ and the $\mathrm{CO}_{2}$ concentration of $10 \%$, and the culture solution was changed every three days. When the cells proliferated to overspread the bottom of the bottle, adherent cells were collected by trypsin digestion and subcultured under the same culture system and conditions to amplify and purify bone marrow MSCs.

\section{Groups}

Cells were divided into five groups. Group A (Blank Control group); Group B (MDA control group): Added MDA with a final concentration of $0.1 \mathrm{mmol} / \mathrm{L}$ in the medium for $24 \mathrm{~h}$; Group C (GS-Rg1 low dose group, L group): Added GS-Rg1 with a final concentration of $10 \mathrm{mg} / \mathrm{L}$ in the medium for $24 \mathrm{~h}$ pretreatment, and then treated with MDA; Group D (GS-Rg1 middle dose group, $\mathrm{M}$ group): Added GS-Rg1 with a final concentration of $50 \mathrm{mg} / \mathrm{L}$ in the medium for $24 \mathrm{~h}$ pretreatment, and then treated with MDA; Group E (GS-Rg1 high dose group, H Group): Added GS-Rg1 with a final concentration of $100 \mathrm{mg} / \mathrm{L}$ in the medium for $24 \mathrm{~h}$ pretreatment, and then treated with MDA. The experiment was repeated three times.

\section{Colony-forming assay}

The MSCs at P3 stage were used for subculture. When the growth of cells reached the fusion status of $70-80 \%$, the solution was changed after treatment. After the cells were 
cultured in vitro for seven days in the incubator, the supernatant was sucked out, washed twice with PBS-EDTA solution, stained with Wright-Giemsa and rinsed gently with distilled water, and dried at the room temperature. When the cells were observed under an inverted microscope, the aggregates of 10 fibroblasts were aggregated into one MSC colony.

\section{MTT assay}

As the procedures mentioned above, MSC colony culture was conducted with 24 -well plate to the 9th day, $50 \mu \mathrm{L}$ MTT solution was added $(5 \mathrm{mg} / \mathrm{mL})$ to each well and continued for $4 \mathrm{~h}$, then the culture was prepared, and the suspension in the wells was cleaned up carefully and $375 \mu \mathrm{L}$ dimethyl sulfoxide (DMSO) was added to each well, and oscillated for 10-20 min to adequately dissolve the crystal methyl. The operation was identical except no cells in the blank control well. The detection wavelength of $490 \mathrm{~nm}$ was selected and the light absorption value (A-value) was recorded.

\section{Flow cytometric analysis}

Cells were inoculated with the cell density of $2 \times 10^{3} / \mathrm{cm}^{2}$ in the cell culture flasks at the volume of $8 \mathrm{~mL}$ for each. The cells were cultured for seven days and dissociated. Single-cell suspension of $2 \times 10^{6}$ cells was added in PBS buffer $(\mathrm{pH}=$ 7.2), centrifuged at $500 \mathrm{~g}$ for $5 \mathrm{~min}$, then discarded the supernatant and repeated twice, and then the cell suspension was placed in 2-3 mL 70\% cold ethanol, blended and kept at $4^{\circ} \mathrm{C}$ for at least $30 \mathrm{~min}$. The samples were added with PI and tested after being centrifuged and washed twice.

\section{BrdU cell proliferation assay}

MSC of P3 generation $\left(1 \times 10^{5} / \mathrm{mL}\right.$ cell density) was inoculated in a $35 \mathrm{~mm}$ plastic culture dish with a cover glass, BrdU (final concentration of $30 \mu \mathrm{mol} / \mathrm{L}$ ) was added after five days of culture, and continued for $2 \mathrm{~h}$. The cover glass was taken out and operated according to the following instructions: washed with PBS buffer for three times and fixed with $4 \%$ paraformaldehyde for $30 \mathrm{~min}$; add $0.3 \% \mathrm{H}_{2} \mathrm{O}_{2}$; Methanol, inactivate endogenous peroxidase, add 5\% normal rabbit serum blocking solution; room temperature was $20 \mathrm{~min}$; formamide $100^{\circ} \mathrm{C}, 5 \mathrm{~min}$ denatured nucleic acid. Mouse anti-BrdUmAb (working concentration 1:250) was added dropwise at $4{ }^{\circ} \mathrm{C}$ overnight. Goat anti-mouse $\operatorname{IgG}(1: 100)$, $37^{\circ} \mathrm{C}, 20 \mathrm{~min}$. plus streptavidin-biotin-peroxidase complex (SABC), $37^{\circ} \mathrm{C}, 20$ min. 3, 3-Diaminobenzidine (DAB) color development, negative control: BrdU-free MSCs cultured under the same conditions. The total number of cells and the number of BrdU-positive cells in 10 high power fields were randomly counted, and the marker index (LI) was calculated. ${ }^{13}$ Labeling index $(\mathrm{LI})=$ number of labeled cells/total number of counted cells $\times 100 \%$.

\section{Fluorescence quantitative PCR}

After the cells in each group were induced and cultured for seven days, RNA was isolated and extracted according to the instructions of Trizol reagent. According to the TaqMan kit, $2 \mu \mathrm{g}$ of RNA was reverse-transcribed into cDNA. PCR reaction conditions: $95^{\circ} \mathrm{C}, 45 \mathrm{~s} ; 94^{\circ} \mathrm{C}, 45 \mathrm{~s} ; 50^{\circ} \mathrm{C}, 45 \mathrm{~s} ; 72^{\circ} \mathrm{C}$, $90 \mathrm{~s} ; 35$ cycles, $72^{\circ} \mathrm{C}$ extension for $10 \mathrm{~min}$. SYBR Green MaterMix reagent was used to detect the mRNA level of the gene to be tested, repeated three times, and mRNA levels were normalized with GAPDH as an internal control. The expression of the gene was quantitatively analyzed by the $\Delta \Delta \mathrm{Ct}$ method. PCR primer sequences are shown in Table 1 .

\section{Western blot analysis}

Cells were washed with cold PBS for three times, cell lysis solution was added, and quickly, the cells from the ice were scraped off. Cells were broken by ultrasound under ice bath conditions, supernatant was sucked out after centrifugation, and protein concentration was measured by BCA. $25 \mu \mathrm{g}$ protein samples were taken out, load buffer was added and water-bathed at $100^{\circ} \mathrm{C}$ for $5 \mathrm{~min}$. After $10 \%$ SDS-PAGE, electrotransferred to the PVDF membrane and sealed in the sealing liquid for $1 \mathrm{~h}$ at room temperature. Incubated with primary antibody $(1: 1000)$ at $4{ }^{\circ} \mathrm{C}$ overnight, the membrane was washed with TBST three times. The incubation was repeated with secondary antibody (1:2000) at room temperature for $1 \mathrm{~h}$, the membrane was washed three times and the image was developed by ECL. The image of the strip was analyzed and the gray value was determined, and the relative expression levels of p21, cyclin E and CDK2 in MSC of each group were expressed by internal reference standardization using $\beta$-actin.

Table 1. Primers used for real-time quantitative PCR analysis.

\begin{tabular}{|c|c|c|}
\hline Primers & & Sequences \\
\hline Cyclin E & $\begin{array}{l}\text { sense } \\
\text { anti-sense }\end{array}$ & $\begin{array}{l}\text { 5' GCTCGGGTGTTGTAGGTTGC3' }^{\prime} \\
5^{\prime} \text { TTGGCTGACAGTGGAGAAGG3' }\end{array}$ \\
\hline CDK2 & $\begin{array}{l}\text { sense } \\
\text { anti-sense }\end{array}$ & 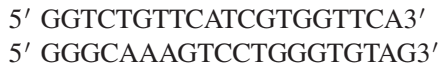 \\
\hline p21 & $\begin{array}{l}\text { sense } \\
\text { anti-sense }\end{array}$ & $\begin{array}{l}5^{\prime} \text { ATACCGTGGGTGTCAAAGCA3' } \\
5^{\prime} \text { CAGGGAGGGAGCCACAATAC3' }\end{array}$ \\
\hline GAPDH & $\begin{array}{l}\text { sense } \\
\text { anti-sense }\end{array}$ & $\begin{array}{l}5^{\prime} \text { AAATGGTGAAGGTCGGTGTG3' } \\
5^{\prime} \text { TGAAGGGGTCGTTGATGG3' }\end{array}$ \\
\hline
\end{tabular}




\section{Statistical analysis}

All statistical analyses were performed using SPSS Version 24.0 (SPSS Inc., Chicago, IL) and graphs were constructed by Sigma Plot. One-way analysis of variance (ANOVA) was used to analyze continuous variables in accordance with normal distribution (presented as $\pm \mathrm{s}$ ). A $P$-value $<0.05$ was considered to be statistically significant.

\section{Results}

\section{GS-Rg1 promoted the colony forming of MSCs}

MSCs at P3 phase of mice were incubated with GS-Rg1 of different concentrations $(10,50$ and $100 \mathrm{mg} / \mathrm{L})$ for $24 \mathrm{~h}$, cultured for nine days and stained with Wright-Giemsa before the treatment with $100 \mu \mathrm{mol} / \mathrm{L}$ MDA. Compared with the MDA group, the number of MSC colonies significantly increased in the $\mathrm{M}$ and $\mathrm{H}$ groups $(P<0.05)$, while the number of MSC colonies increased in L group but not statistically significant $(P>0.05)$ (Table 2).

\section{GS-Rg1 promoted the cell viability of MSCS passage and amplification}

As is shown in Fig. 1, the light absorption value (A490 value) was significantly lower in MDA group compared with the blank control group $(P<0.01)$, while in the M $(50 \mathrm{mg} / \mathrm{L})$ and $\mathrm{H}(100 \mathrm{mg} / \mathrm{L})$ groups, the A490 levels were much higher than that in the MDA group $(P<0.05)$. Compared with the MDA group, the A490 level in the $\mathrm{L}(10 \mathrm{mg} / \mathrm{L})$ group was higher but not statistically significant (Fig. 1).

\section{Flow cytometry analysis of bone marrow MSCs cycle in mice under GS-Rg1}

The proportion of cells in each cell cycle was demonstrated in Table 3. Compared with the MDA group, the proportion of

Table 2. The number and area of MSC colonies cultured at different concentrations of GS-Rg1.

\begin{tabular}{llll}
\hline & \multicolumn{3}{c}{ MSC colony } \\
\cline { 2 - 4 } & $\begin{array}{c}\text { Number } \\
\text { (colonies } / 1 \times 10^{6} \\
\text { BMMNC) }\end{array}$ & $\begin{array}{c}\text { Mean area } \\
\left(\mathrm{mm}^{2} / \text { colony }\right)\end{array}$ & $\begin{array}{c}\text { Number of } \\
\text { cells/colony }\end{array}$ \\
\hline 0 (control) & $33.67 \pm 6.18$ & $1.51 \pm 0.28$ & $342.98 \pm 25.69$ \\
MDA control & $18.92 \pm 3.61 \# \#$ & $0.79 \pm 0.16^{\# \#}$ & $178.24 \pm 14.62 \# \#$ \\
Rg1 Low dose (L) & $19.34 \pm 1.96$ & $1.12 \pm 0.09^{*}$ & $182.56 \pm 8.39$ \\
Rg1 Middle & $27.94 \pm 4.42^{*}$ & $1.32 \pm 0.21^{* *}$ & $234.74 \pm 19.69^{*}$ \\
$\quad$ dose $(\mathrm{M})$ & & & \\
Rg1 High dose (H) & $26.48 \pm 3.67 *$ & $1.35 \pm 0.11^{* *}$ & $267.54 \pm 15.69^{* *}$ \\
\hline
\end{tabular}

Note: \#\#: $P<0.01$, compared with the control group; $* * P<0.01$; $* P<0.05$, compared with MDA-treated, BMMNC, bone marrow mononuclear cell. $n=3$.

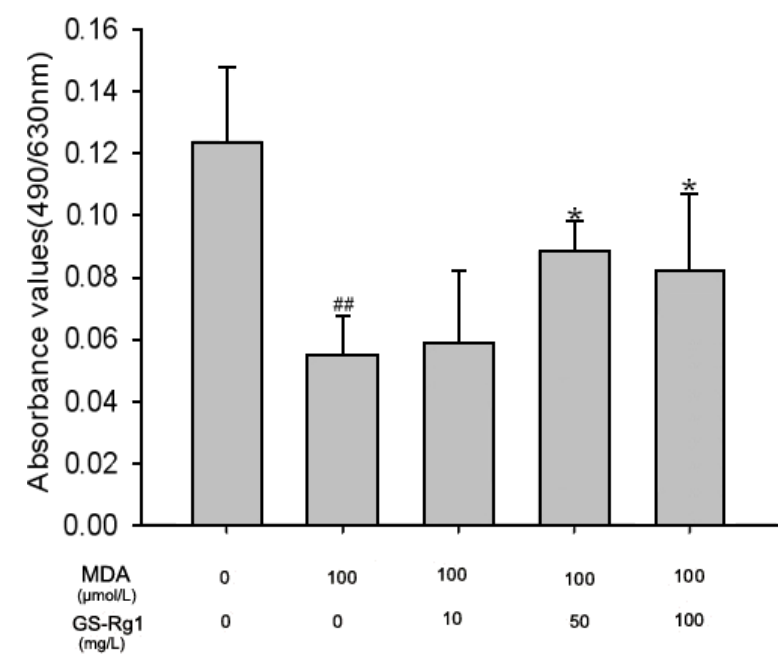

Figure 1. Effect of GS-Rg1 on cell viability in MSC cultures. Note: \#\#: $P<0.01$, compared with the control group; *: $P<0.05$, compared with the MDA-treated group; $* *: P<0.01$, compared with the MDA-treated group.

cells decreased at $G 0 / G 1$ phase while increased at $S+G_{2} / M$ phase with statistical significance $(P<0.05)$.

Flow cytometry was used to detect the DNA content of mouse bone marrow MSCs cultured in different concentrations of GS-Rg1. The percentage of cells in each cell cycle was obtained by computer processing. Compared with MDA control group, GS-Rg1 with the pretreatment group, the proportion of cells in $G 0 / G 1$ phase decreased, and the proportion of cells in $S+G 2 / M$ phase increased, the difference was significant $(P<0.05)$.

\section{GS-Rg1 increased the percentage of BrdU positive cells in MSCs subculture}

The percentage of BrdU positive cells significantly decreased in the MDA group compared with the normal control group $(P<0.01)$. When treated with different concentrations of GS-Rg1, the percentage of BrdU positive cells significantly increased (L, $\mathrm{M}$ and $\mathrm{H}$ groups) compared with the MDA group (Fig. 2).

Table 3. Cell cycle status of bone MSCs in mice cultured at different concentrations of GS-Rg1.

\begin{tabular}{llll}
\hline & \multicolumn{3}{c}{ Cell cycle/\% } \\
\cline { 2 - 4 } Groups & \multicolumn{1}{c}{$G_{0} / G_{1}$} & \multicolumn{1}{c}{$G_{2} / M$} & \multicolumn{1}{c}{$S$} \\
\hline 0 (control) & $83.47 \pm 4.35$ & $5.51 \pm 0.97$ & $11.02 \pm 1.46$ \\
MDA control & $94.14 \pm 5.67 \# \#$ & $1.08 \pm 0.36^{\# \#}$ & $4.78 \pm 1.13^{\# \#}$ \\
Rg1 Low dose $(\mathrm{L})$ & $92.49 \pm 4.79$ & $2.05 \pm 0.59$ & $5.46 \pm 0.95$ \\
Rg1 Middle dose(M) & $88.91 \pm 7.36^{*}$ & $2.63 \pm 0.48^{*}$ & $8.46 \pm 1.23^{*}$ \\
Rg1 High dose(H) & $86.59 \pm 5.02^{* *}$ & $4.22 \pm 0.73^{* *}$ & $9.19 \pm 0.78^{* *}$ \\
\hline
\end{tabular}

Note: \#\#: $P<0.01$, compared with the control group; *: $P<0.05$, compared with the MDA-treated group; $* *: P<0.01$, compared with the MDAtreated group. 


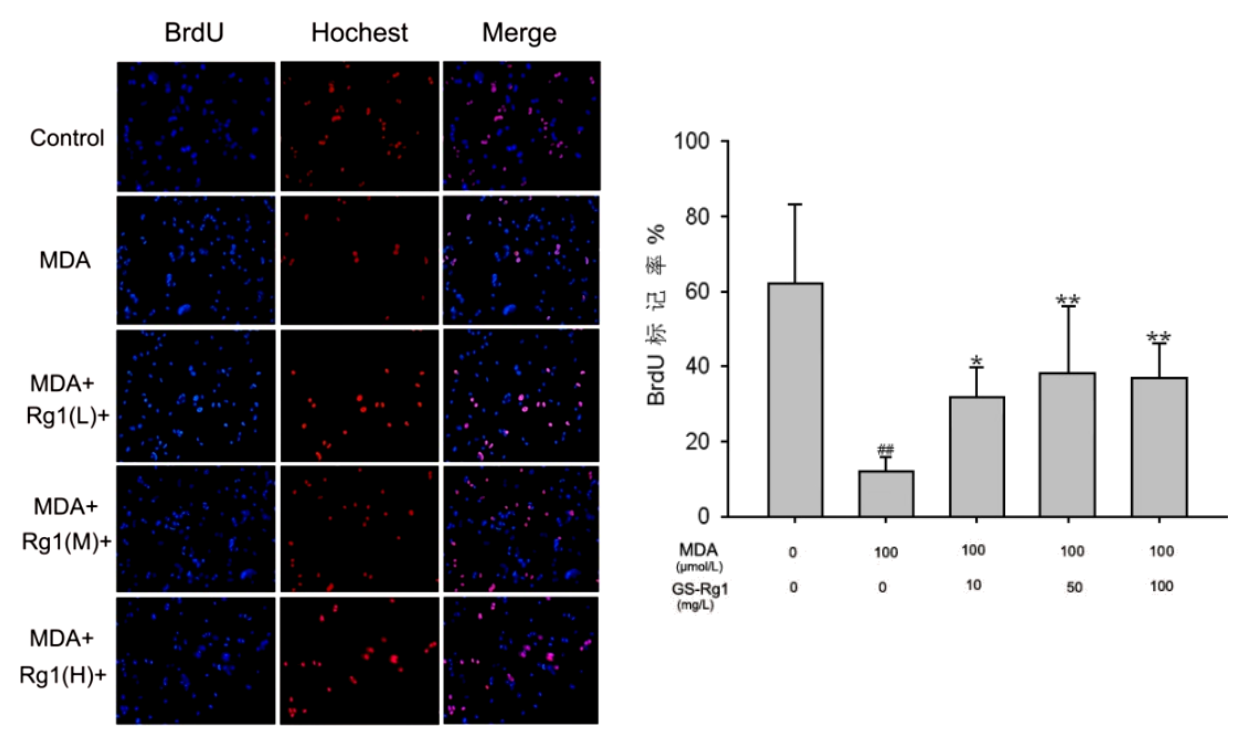

Figure 2. Effect of GS-Rg1 on percentage of BrdU-positive cells.

Note: \#\#: $P<0.01$, compared with the control group; *: $P<0.05$, compared with the MDA-treated group; **: $P<0.01$, compared with the MDA-treated group.

\section{GS-Rg1 upregulated the expression of CDK2}

As is shown in Fig. 3, when compared with the normal control group, the expression of CDK2 mRNA and proteins significantly decreased in the MDA group, while in the M and $\mathrm{H}$ groups, the expression of CDK2 mRNA and proteins significantly increased when compared with the MDA group.

\section{GS-Rg1 downregulated the expression of p21}

As is shown in Fig. 4, compared with the normal control group, the expression of p21 mRNA and proteins in the

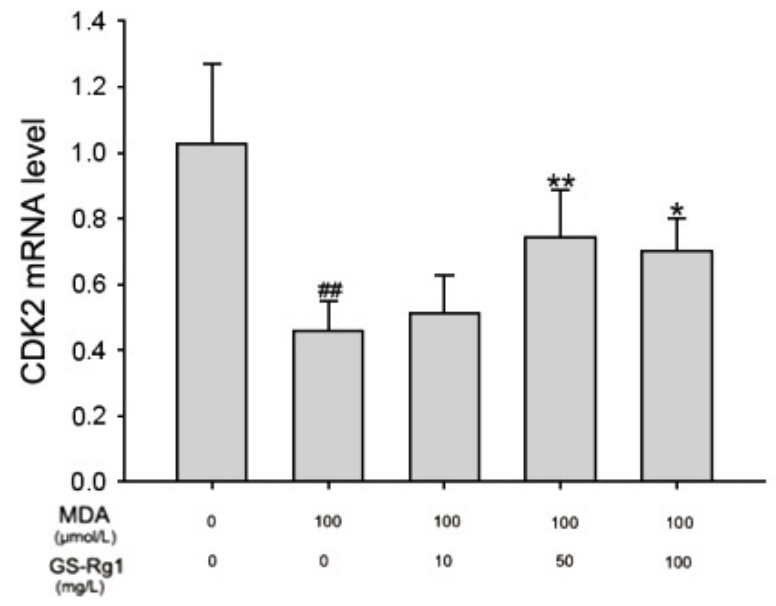

MDA group significantly increased, while compared with the MDA group, the expression of p21 mRNA and proteins significantly decreased in different concentrations of GS-Rg1 groups (L, M and $\mathrm{H}$ groups), and with the increase of GS$\mathrm{Rg} 1$ concentration, the expression of $\mathrm{p} 21 \mathrm{mRNA}$ and proteins decreased in a dose-dependent manner.

\section{GS-Rg1 upregulated the expression of cyclin $E$}

As is shown in Fig. 5, compared with the normal control group, the expression of cyclin E mRNA and proteins in the

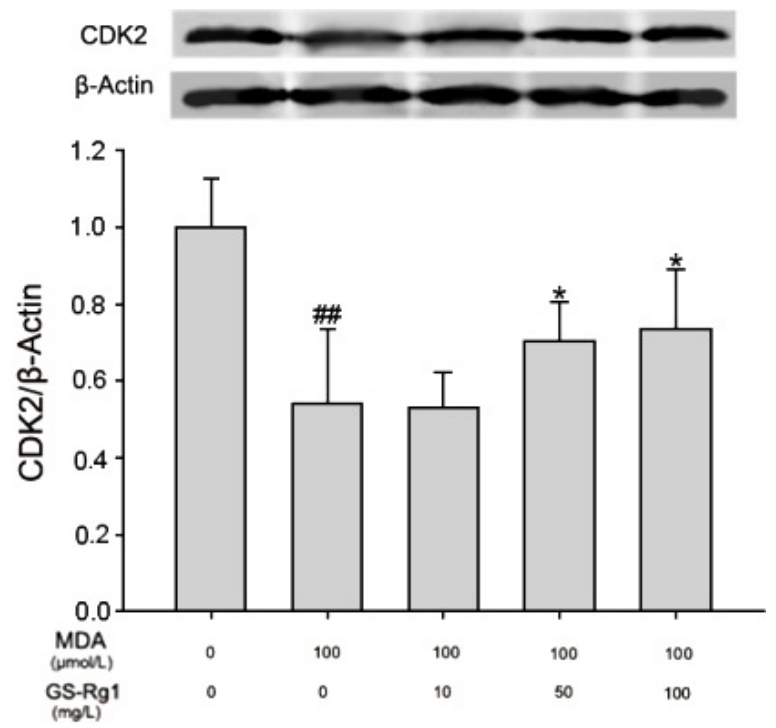

Figure 3. Effect of GS-Rg1 on CDK2 mRNA and protein expressions.

Note: \#\#: $P<0.01$, compared with the control group; *: $P<0.05$, compared with the MDA-treated group; **: $P<0.01$, compared with the MDA-treated group. 


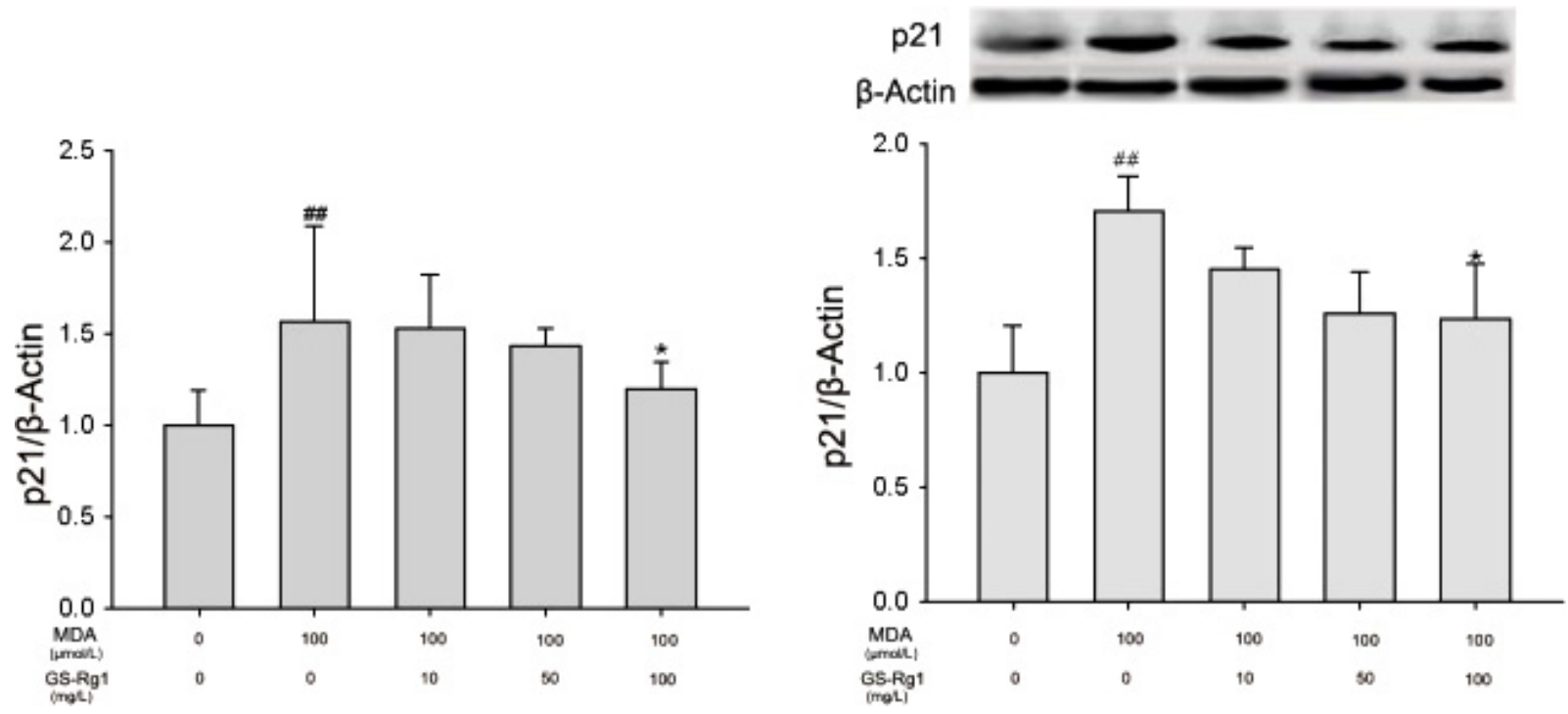

Figure 4. Effect of GS-Rg1 on $p 21 \mathrm{mRNA}$ and protein expressions.

Note: \#\#: $P<0.01$, compared with the control group; *: $P<0.05$, compared with the MDA-treated group; **: $P<0.01$, compared with the MDA-treated group.
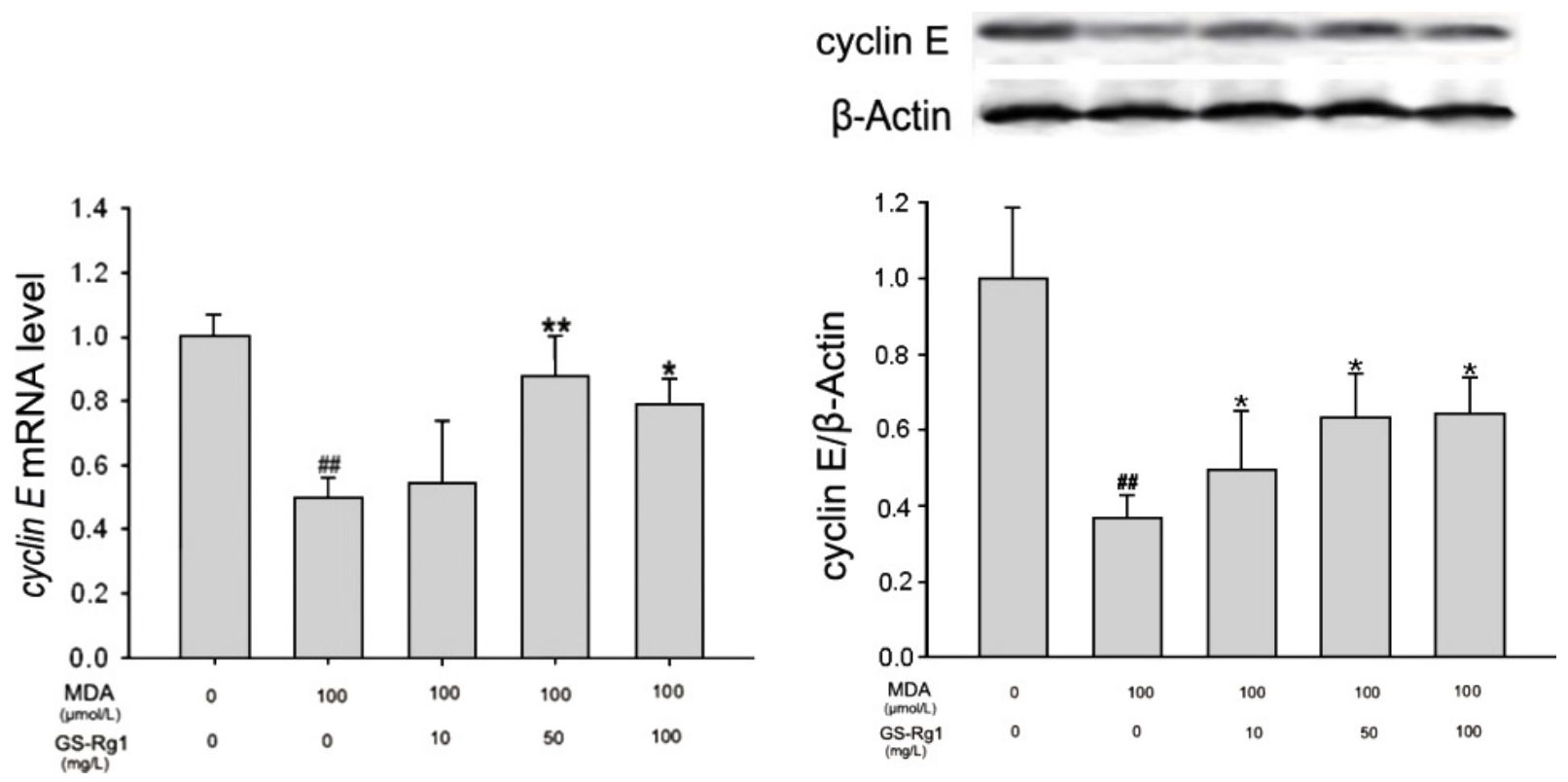

Figure 5. Effect of GS-Rg1 on cyclin E mRNA and protein expressions.

Note: \#\#: $P<0.01$, compared with the control group; *: $P<0.05$, compared with the MDA-treated group; **: $P<0.01$, compared with the MDA-treated group.

MDA group significantly increased. When compared with the MDA group, the expression of cyclin E mRNA and proteins in the $\mathrm{M}$ and $\mathrm{H}$ groups decreased with statistical significance $(P<0.05)$.

\section{Discussion}

Our results showed that GS-Rg1 could increase the colonyforming ability, the passage and amplification activity of
MSCs, the percentage of BrdU into positive MSCs, as well as the expression of cyclin E and CDK2, while reduce the expression of $\mathrm{p} 21$, which suggested that GS-Rg1 had a protective effect on MDA inhibiting MSCs proliferation in mice in vitro, and this protective effect was related to the expression of cyclin E, CDK2 and p21.

Cell cycle is the basic process of cell life. With the change of cell cycle phase, cells enter the physiological status such as proliferation, differentiation, senescence and death. The cell 
cycle runs orderly according to the $G 1-S-G 2-M$ sequence. $G 1$ phase is the key to start the cell cycle. Cell cycle is regulated by a variety of factors. Cyclins and CDKs constitute the core of cell cycle regulation system and play an important role in the positive regulation, while CDIKs negatively regulate CDKs.

The most remarkable feature of cellular senescence is that cells maintain metabolic activity for a long period of time. However, due to the retardation in $G 1$ phase, cells lost the ability to react to mitogen and synthesize DNA and thus could not enter the $S$ phase. In senescent fibroblasts, cyclin, CDK and CDIKs changed in quantity and activity.

Cyclin E is a cyclin of the $G 1$ phase. At the junction of $G 1$ phase and $S$ phase, Cyclin E combines with CDK2 to form a complex to exert its protein kinase activity, which is the key cyclin of helping cells enter $S$ phase from $G 1$ phase. Our study showed that compared with the MDA group, the protein expression levels of cyclin E and CDK2 in the GS-Rg1 pretreatment group significantly increased, while the proportion of cells in $G 1$ phase significantly reduced, which suggested that GS-Rg1 might postpone cellular senescence by upregulating the expression of cyclin E and CDK2 and leading cells enter the $S$ phase.

p2l protein is a cyclin-dependent kinase inhibitor (CKI) which is known to have the most extensive kinase inhibitory activity. p2l protein plays an important role in keeping cells stagnating in the $G 1$ phase and blocking cells from entering the S phase. p2l can extensively bind and inhibit the phosphorylation activity of various cyclin-CDK compounds, ${ }^{14}$ negatively regulate the function of cyclin-CDK2, reduce the phosphorylation of retinoblastoma $(\mathrm{Rb})$ protein, and ultimately inhibit the synthesis of DNA, so that cells cannot enter the $S$ phase and stagnate in the $G 1$ phase, and characteristic changes of cell senescence occur. ${ }^{15}$ Meanwhile, the binding site of proliferating cell nuclear antigen (PCNA) can be found on $\mathrm{p} 21$ protein chain. PCNA is the $\varepsilon$ and $\delta$ co-factor of DNA polymerase, and is indispensable in the synthesis of DNA. PCNA can promote the extension of DNA chain. PCNA starts to increase in the $G l$ phase of DNA synthesis, peaks in the $S$ phase, and rapidly decreases in the $G 2 / M$ phase, which is considered as a judging indicator of cell proliferation under both normal and diseased conditions, and the change of its content is consistent with DNA synthesis. The expression of PCNA is necessary for cells entering the cell cycle and completing the DNA replication and division. The protein expression of PCNA in the inactive cells is very low, while in the proliferative cells, it is remarkably increased. p21, when combined with PCNA, can prevent the extension of DNA polymerase, make DNA polymerase fall off the DNA synthesis template, and thus directly inhibiting the PCNA-dependent DNA replication. In senescent cells, it was found that the mRNA of p2l increased over 10-20 times when compared with that in normal cells. ${ }^{16}$ Therefore, p21 plays a key role in the cell senescence. The results of our study confirmed that the expression of p21 protein in MDA group significantly increased, the proportion of cells in the $G 1$ phase significantly increased, and the proportion of cells in the $S$ phase significantly decreased; however, after GS-Rg1 treatment, the expression of p21 significantly decreased, the proportion of cells in the $G 1$ phase significantly decreased, and the proportion of cells in the $S$ phase significantly increased, which as a whole suggested that the anti-cellular senescence of GS-Rg1 is related to downregulating the expression of $\mathrm{p} 21$.

In conclusion, the results of this study suggested that GS-Rg1 had a protective effect on MDA inhibiting the proliferation of MSCs, which was probably related to the changes in the expression of cyclin E, CDK2 and p2l.

\section{Conflict of Interest}

The authors declare no conflict of interest.

\section{Acknowledgments}

This project was supported by the Hunan Provincial Science and Technology Plan General Project Funding (N2013FJ3016), 2013 Hunan Provincial Department of Education Science Research Youth Project (13B070), Changsha Science and Technology Plan Project People Health Technology Support Fund Special (K1303026-31).

\section{References}

1. Williams AR, Hare JM. Mesenchymal stem cells: Biology, pathophysiology, translational findings, and therapeutic implications for cardiac disease. Circ Res 2011;109(8):923-40.

2. Guo ZK, Liu XD, Hou CM, Li XS, Mao N. Human bone marrow mesenchymal stem cells differentiate into neuron-like cells in vitro. Zhongguo Shi Yan Xue Ye Xue Za Zhi 2001;9(1):91-2.

3. Wang YC, Zhang Y, Proliferative capacity of mesenchymal stem cells from human fetal bone marrow and their ability to differentiate into the derivative cell types of three embryonic germ layers. Sheng Li Xue Bao 2008;60(3):425-30.

4. Fehrer $C$, Lepperdinger $G$, Mesenchymal stem cell aging. Exp Gerontol 2005;40(12):926-30.

5. Justesen J, Stenderup K, Kassem MS, Mesenchymal stem cells. Potential use in cell and gene therapy of bone loss caused by aging and osteoporosis. Ugeskr Laeger 2001;163(40):5491-5.

6. Bonab MM, Alimoghaddam K, Talebian F, Ghaffari SH Ghavamzadeh A, Nikbin B. Aging of mesenchymal stem cell in vitro. BMC Cell Biol 2006;7(1):14

7. Montjean D, Ménézo Y, Benkhalifa $\mathrm{M}$ et al. Malonaldehyde formation and DNA fragmentation: Two independent sperm decays linked to reactive oxygen species. Zygote 2010;18(3) $265-8$ 
8. Ozgocmen S, Kaya H, Fadillioglu E, Aydogan R, Yilmaz Z. Role of antioxidant systems, lipid peroxidation, and nitric oxide in postmenopausal osteoporosis. Mol Cell Biochem 2007;295(1-2):45-52.

9. Chen XC, Zhu YG, Zhu LA et al. Ginsenoside Rg1 attenuates dopamine-induced apoptosis in $\mathrm{PC} 12$ cells by suppressing oxidative stress. Eur J Pharmacol 2003;473(1):1-7.

10. Chen XC, Zhou YC, Chen Y, Zhu YG, Fang F, Chen LM. Ginsenoside Rg1 reduces MPTP-induced substantia nigra neuron loss by suppressing oxidative stress. Acta Pharmacol Sin 2005;26(1):56-62.

11. Wu DM, Song YF. Effect of ginsenoside-Rg1 on the proliferation of paraurethral fascia fibroblasts derived from women suffering from stress urinary incontinence. Zhonghua Fu Chan Ke Za Zhi 2008;43(11):835-8.

12. Korivi M, Hou CW, Huang CY et al. Ginsenoside-Rg1 protects the liver against exhaustive exercise-induced oxidative stress in rats. Evid Based Complement Alternat Med 2012;2012: 932165
13. Nakamura S, Takeda Y, Kanno M et al. Application of bromodeoxyuridine (BrdU) and anti-BrdU monoclonal antibody for the in vivo analysis of proliferative characteristics of human leukemia cells in bone marrows. Oncology 1991;48(4):285-9.

14. Roy S, Kaur M, Agarwal C, Tecklenburg M, Sclafani RA, Agarwal R. P21 and p27 induction by silibinin is essential for its cell cycle arrest effect in prostate carcinoma cells. Mol Cancer Ther 2007;6(10):2696-707.

15. Wong SHK, Zhao Y, Schoene NW, Han CT, Shin RS, Lei Ky. Zinc deficiency depresses p21 gene expression: inhibition of cell cycle progression is independent of the decrease in p21 protein level in HepG2 cells. Am J Physio Cell Physiol 2007;292(6):C2175-84.

16. Ma Y, Prigent SA, Born TL, Monell CR, Feramisco JR, Bertolaet BL. Microinjection of anti-p21 antibodies induces senescent Hs68 human fibroblasts to synthesize DNA but not to divide. Cancer Res 1999;59(20):5341-8. 